\title{
Remediation Studies Of Heavy Metal Ions Cd, Pb And Hg From Its Solutions By Precipitating Out With Natural Biological Fluid Cows (Bosindicus) Urine And Subsequent Analysis Of Filtrate By ICP-AES And GC-MS Analysis.
}

\author{
Debasish.Mitra \\ ( Radiation Technology Development Division, Bhabha Atomic Research Centre, Mumbai, India)
}

\begin{abstract}
Natural biological fluid Cows(Bosindicus) urine precipitates out the toxic heavy metal ions when added to450ppm-21660ppm ranges in the solution of toxic heavy metals like Cadmium, Lead and Mercury. The dried residue was tested by Energy Dispersion X Ray Fluorescence for presence of these metals and found positive. The filtrate solution were analyzed the ICP-AES results show that there is almost 3000 times decrease for cadmium and for Lead and Mercury it is 320 times decrease for Lead and 360 times for Mercury, the dilution factor has been taken account for the results.. The filtrate solution were also analyzed by GC-MS and compared to GC-MS chromatogram of cow's urine to find the ingredients responsible for precipitations. However, it seems alkaline $\mathrm{pH}$ of cow's urine is one of the causes responsible for the precipitations apart from synergistic effects of so many ingredients of cows urine. The use of natural biological fluid like cows urine heralds a new precipitating agent which is biodegradable and highly environmental friendly. The results of this experiment will have far reaching impact in metal processing industry of these heavy metals, detoxification of heavy metals ions in the solution in bulk quantities since cows urine are available in plenty.
\end{abstract}

KeyWords: Cows urine, Heavy Metals, Remediation, ICP-AES, ED.X Ray Fluorescence, GC-MS.

\section{Introduction.}

The discharge of heavy metals like cadmium, lead and mercury from natural and anthropogenic activities like industrial activities cause the accumulation of heavy metals into the environment. Soil is the major reservoir for most of the metals. These heavy metals, they interact with plant roots and subsequently enter the food chain of animals and human. It is reported terrestrial foods account for $98 \%$ of ingested food toxic heavy metals, while $1 \%$ of aquatic foods and drinking water[1]. The remediation of soils contaminated with heavy metals can be performed using chemical, physical and biological techniques.[2]. Finally these heavy metal ions can also drift to water system and make in natural eco water cycle disruption. The effect of toxic metals on human health has been described in detail [3]. The toxicity of heavy metals is due to the fact it does not get metabolized in the body. In the present work natural biological fluid cows urine has been tried for the first time to precipitate out from water soluble salts of Cadmium Nitrate, Lead Nitrate and Mercury Nitrate from its solutions. It has been observed cows urine the $\mathrm{pH}$ of which is 9-10 and UV absorption at $298 \mathrm{~nm}$. can immediately precipitate out these metal ions from its salts solutions.The dried residue after filtration has been detected by Energy Dispersion X-ray fluorescence analysis for $\mathrm{Cd}, \mathrm{Pb}$ and $\mathrm{Hg}$. respectively and test were found to be positive. ICP_AES (Inductively Coupled Plasma Atomic Emission Spectroscopy) analysis were also carried out to determine quantitative diminution of metal ions from the control solutions of these heavy metal ions. The filtrates and cows urine were analyzed by SHIMADZU. GC-MS QP PLUS 2010 to find the patterns of GC-MS chromatogram. to ascertain whether and how ingredients of cows urine actually taking part in the reaction with metal salts. The threshold limit for the toxic elements as defined by FAO/WHO expert committee PTWI( provisional tolerable weekly intake) is $4 \mu \mathrm{g} / \mathrm{Kg}$ body wt. for Mercury for cadmium it is $7 \mu \mathrm{g} / \mathrm{Kg}$ body wt and for Lead it is $25 \mu \mathrm{g} / \mathrm{Kg}$ body wt.

\section{Experimental}

Cows urine were obtained from local Cow shed and cows urine taken from Indian desi cow (Bosindicus) its $\mathrm{pH}$ was measured. The $\mathrm{pH}$ of cows urine varies between 9-10. and UVabsorption was measured at $298 \mathrm{~nm}$. The nitrate salts of Cadmium, Lead and Mercury were obtained from local sd fine chemicals,Mumbai. India.

450ppm solution of $\mathrm{Cd}$ ion in Cadmium nitrate salt solution, 960ppm of $\mathrm{Pb}$ ion in lead nitrate salt solution and 21660ppm of Hg ion in Mercury nitrate salt solutions were made separately in nano pure water. In $100 \mathrm{ml}$ of these salts solution $20 \mathrm{ml}$ of cows urine was added. This leads to immediate precipitation of these metal ions . After 1-2 hour of settling down of the precipitates the solution was filtered. The residue in the filter paper was given several times wash and dried subsequently tested for presence of metal by Energy dispersion X ray 
fluorescence using Jordan valley instrument of Israel based company. The detection was found to be positive, for Cadmium, Lead and Mercury. The filtrate solutions were tested for ICP-AES using JY238Jobin Yohn instrument French based company.,for quantitative estimation of presence of these metal ions in the solutions and compared with that of controls .The result of ICP-AES are summarized in the Table-1 .The GC-MS of cows urine were taken as per the method [4]the different ingredients found were according[5,6].The GC-MS chromatogram of the cows urine and the filtrates of different salts are shown in Figures 1,2,3 and 4 below. The patterns are slightly different for different salt solutions and in case of mercury nitrate one compound was found in the filtrate Mercury chlorphenyl $\mathrm{C}_{6} \mathrm{H}_{5} \mathrm{ClHg}$.Molwt314. as shown in Fig.5

\section{Results}

Table1

\begin{tabular}{|c|c|c|c|c|}
\hline Sr.No & Sample-Id & $\begin{array}{l}\text { Conc. } \\
\text { Control } \\
\text { ion in its } \\
\text { solution in } \\
\text { ppm }\end{array}$ & $\begin{array}{l}\text { Conc.ofControl } \\
\mathrm{Pb} \text { ion in its } \\
\text { salt solution of } \\
\text { in ppm }\end{array}$ & $\begin{array}{l}\text { Conc } \\
\text { ofcontrolHg } \\
\text { in its salt } \\
\text { solution } \\
\text { ppm }\end{array}$ \\
\hline 1 & $\mathrm{Cd}$ & 450 & 960 & 21660 \\
\hline 2 & $\begin{array}{l}\text { Cd- after Treatment } \\
\text { With cows urine. In } 100 \mathrm{ml} \\
\text { of Cd salt solution } 20 \mathrm{ml} \text { of } \\
\text { cows' urine was added. }\end{array}$ & $0.15 \mathrm{ppm}$ & & \\
\hline 3 & $\begin{array}{l}\mathrm{Pb} \text {-after treatment with } \\
\text { cow's urine. In } 100 \mathrm{ml} \text { of } \\
\mathrm{Pb} \text { salt solution } 20 \mathrm{ml} \text { of } \\
\text { cow's urine was added. }\end{array}$ & & 3 & \\
\hline 4 & $\begin{array}{l}\text { Hg-after treatment with } \\
\text { cows urine In } 100 \mathrm{ml} \text { of } \mathrm{Hg} \\
\text { salt solution } 20 \mathrm{ml} \text { of cows } \\
\text { urine was added. }\end{array}$ & & & 60 \\
\hline
\end{tabular}
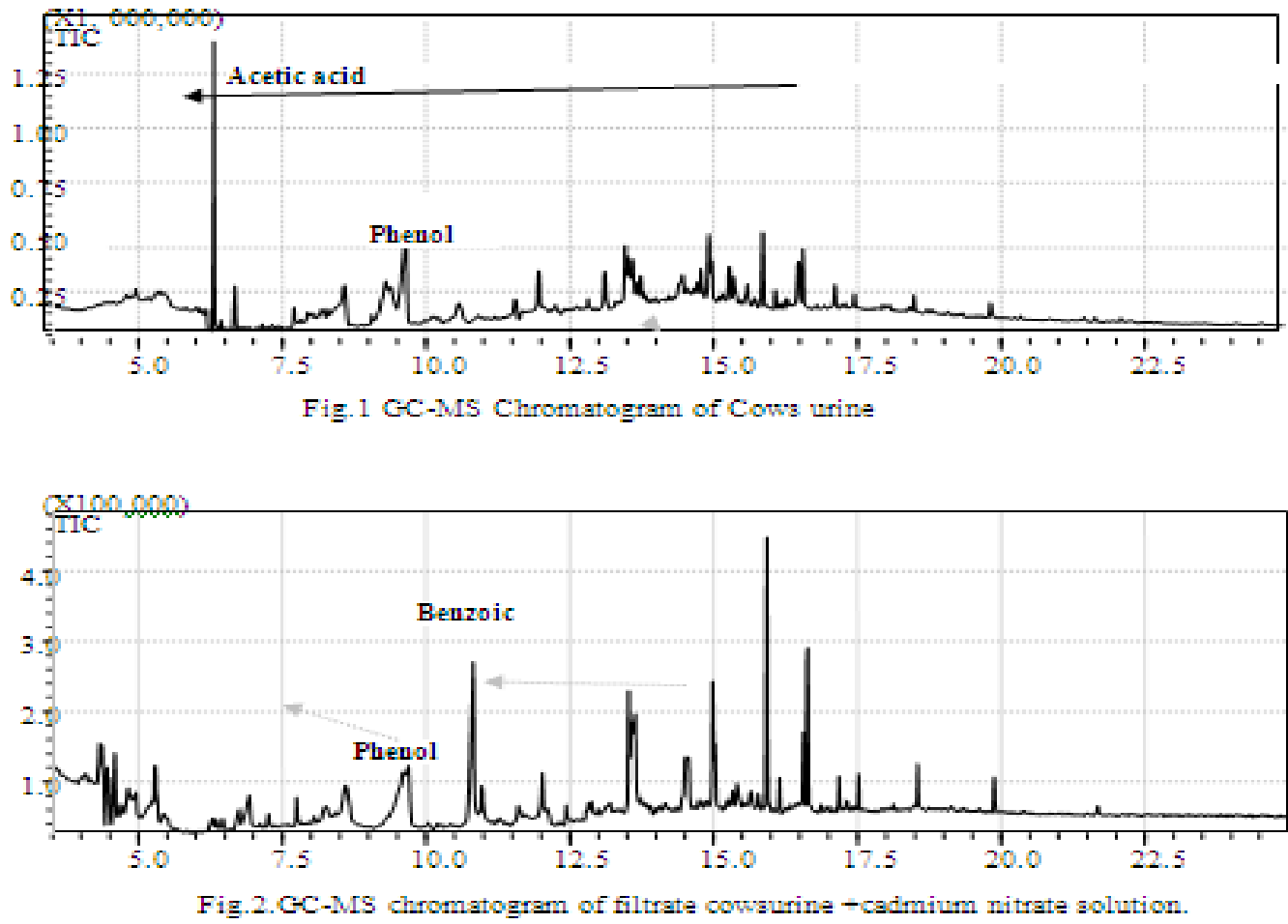


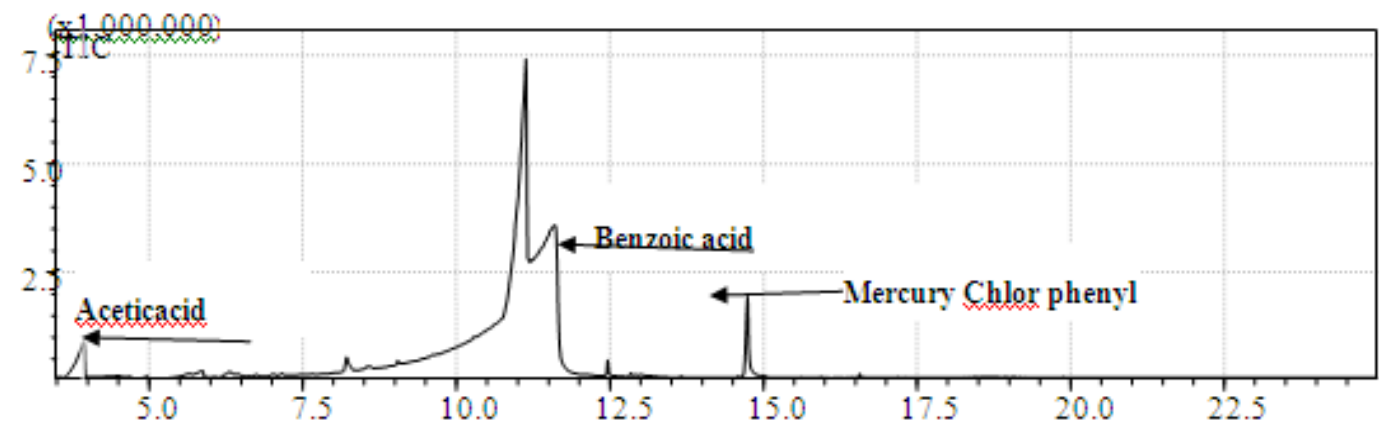

Fig.3.GC-MS chromatogram of filtrate Cowsurine +Mercury Nitrate solution

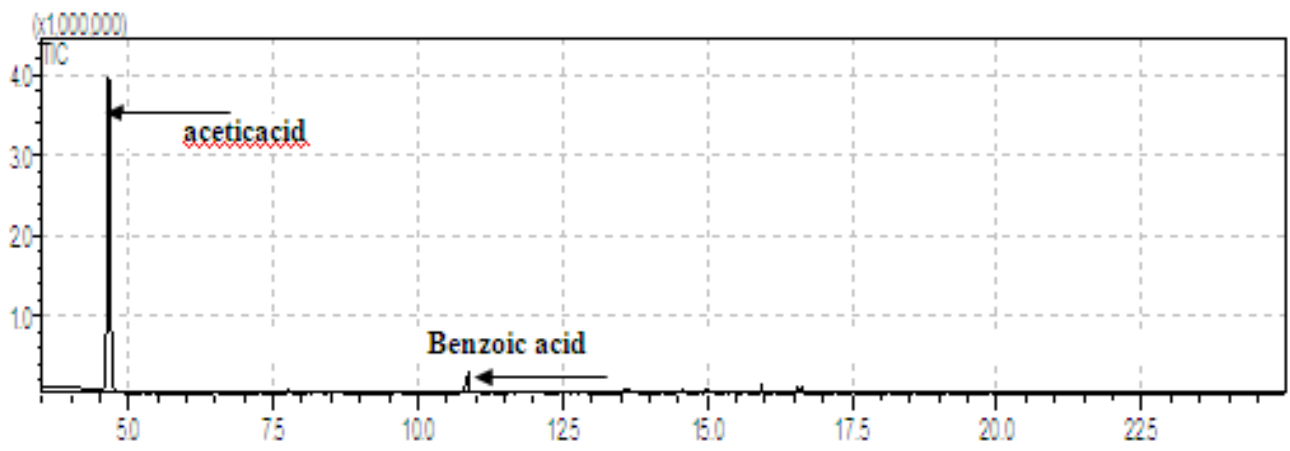

Fig.4.GC-MS chromatogram of filtrate Cows urine +Lead Nitrate solution

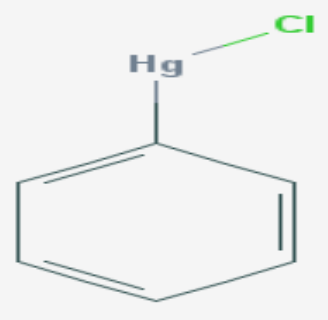

Fig.5 Structure of Agrenal (Mercurychlorphenyl)

\section{Discussion}

The cows urine contains lot of ingredients this includes acetic acid , phenol, uric acid hipuric acid, urea, $\mathrm{Au}($ Gold)hydroxide and several biochemical compounds so actually which compounds are responsible for the precipitations is difficult to predict at present level of work. It may due to synergistic effect of so many compounds along with alkaline $\mathrm{pH}$ of the cows urine which is between 9-10, arising due to presence of urea $2.5 \%$ content since profuse precipitation of the above salts in alkaline medium takes place. The conc. range this reactions spontaneously takes place is 500ppm and above and as we go down like near 100ppm or below the solution becomes turbid and it takes 24 hours to settle out residue of the metals as observed in the experiments so far. Metal ions of Cadmium and Lead and Mercury are precipitated by adding cows urine after filtration the filtrate solutions tested by GC-MS analysis did not show any compound linked with the metal ion. Thus most of the metal ions have gone with the precipitates. However in the case of Mercury one compound Mercury chloro Phenyl $\mathrm{C} 6 \mathrm{H} 5 \mathrm{HgCl}$ as shown in Fig.5, which is useful as pesticide. was found.. The colored pictures of the precipitate had been shown for the Metal ions $\mathrm{Hg}, \mathrm{Pb}$ and $\mathrm{Cd}$ in.Fig.6 


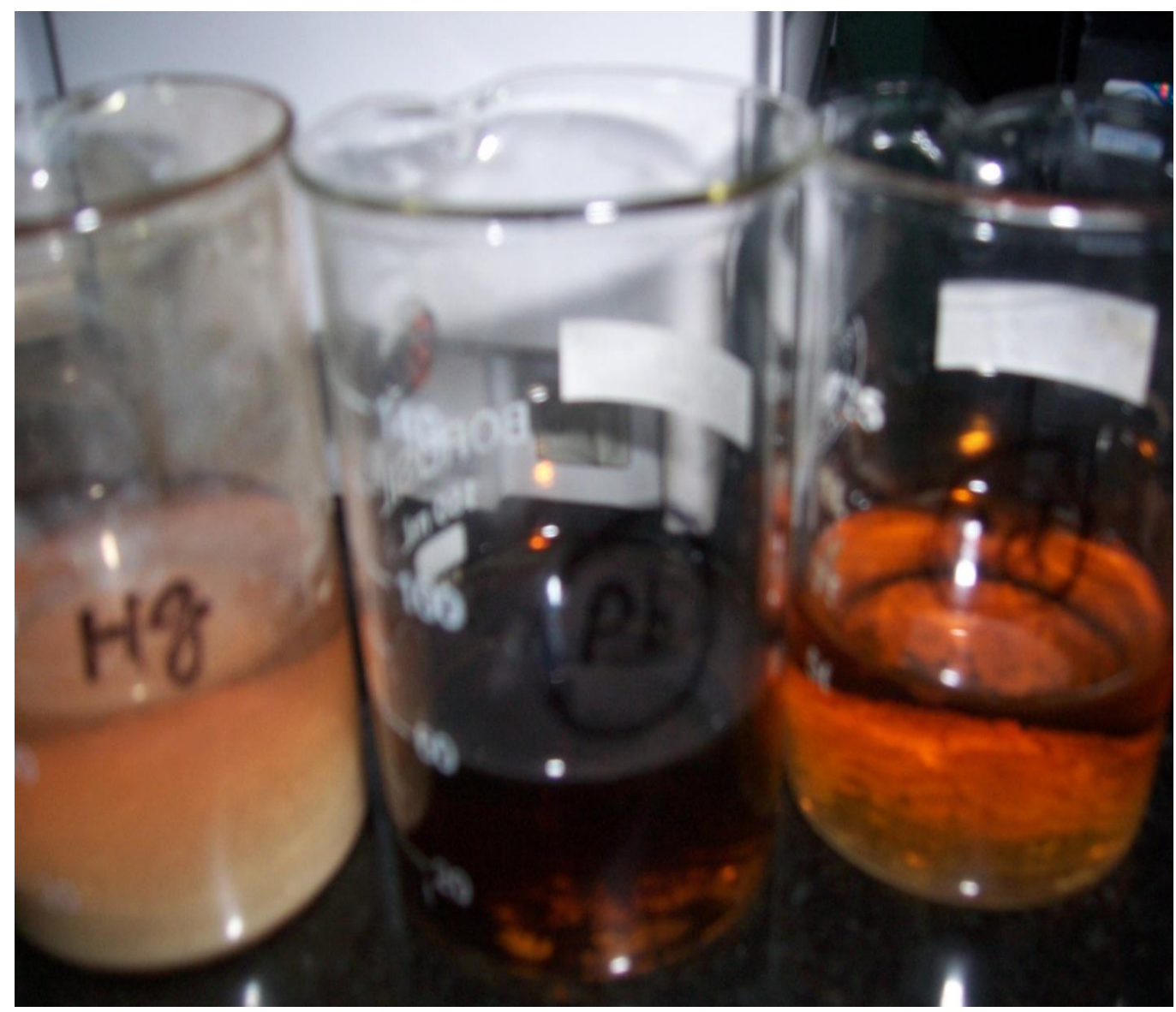

Fig.6The coloration of metal ions after addition of cows' urine in the order from left to right $\mathrm{Hg}$, $\mathrm{Pband} \mathrm{Cd}$.

\section{Conclusion.}

Thus cow's urine can be used as natural reagent for precipitating out these toxic heavy metals from its solution and can be used for its detection also, since color of the precipitate depends on the types of metal ions. The remote villages where availability of synthetic reagents are not there any water samples from bore well or ground well or water samples of any reservoir can be tested for these metal ions simply by adding cows urine and the experiments which even a layman can do that. The cow urine is natural medicine in Ayurvedic system of Indian Medicine and it is consumed by humans as a medicine. It is also used in age old tradition of soil conditioning in Indian system of agriculture and in Modern organic farming system[6] It is biodegradable and germicidal. It is cheap rate in India is Rs. 10 per litre with huge population of cows, Buffalos all over the world the urine of it can be utilized for detoxification of heavy metal ions from the solutions and for its detection. Hence cow should be revered by all because not only its milk nourishes all human society but its urine is so valuable that even in era of Modern Science and Technology it can be used for remediation of heavy metals and thus alleviating environmental pollution and thus cows should not be sent to slaughter houses. These above experiments can be given trial for other toxic metals of periodic table like Cesium and Arsenic and of lanthanides and actinides series of elements.

\section{References}

[1]. F.Vanassche andH.ClijistersH, PlantCell Environ 13(1990)195-206.

[2]. M.P. De-Souza,C.P.A. Huang, N.Chee and N.TerryPlanta2009:259-263

[3]. Varsha Mudgal, Nidhi Madan, Anurag Mudgal,R.B.Singh and SanjayMisra The Open Nutraceuticals Journal 2010,3,94-99

[4]. K.KrishnaMurthy andT.Chakrabarti Biomedical anEnvironmentalSciences17(2004)247-256

[5]. K.Ramesh Kumar,G.Archunan Veterniary Research Communications 24(2000) 445-454

[6]. H.Bhaduria.cow urine -A Magical therapy.Vishwa Ayurveda Parishad Int J cow science (2002)71-74 